\title{
A New-born with Severe Hydrocephalus and Myelomeningocele Associated with Maternal Antiepileptic Medication: A Case Report
}

Soo Kyung Nam ${ }^{1}$, Juyoung Lee ${ }^{1,2^{*}}$ and Yong Hoon Jun ${ }^{1,2}$

${ }^{1}$ Department of Pediatrics, Inha University Hospital, Incheon, Korea

${ }^{2}$ Department of Pediatrics, Inha University School of Medicine, Incheon, Korea

"Corresponding author: Juyoung Lee, Department of Pediatrics, Inha University School of Medicine, Incheon, Korea, Tel: +82-32-890-3506; E-mail: juyounglee@inha.ac.kr

Received date: July 19, 2017; Accepted date: July 22, 2017; Published date: July 25, 2017

Copyright: ( 2017 Lee J, et al. This is an open-access article distributed under the terms of the Creative Commons Attribution License, which permits unrestricted use, distribution, and reproduction in any medium, provided the original author and source are credited.

\begin{abstract}
The possible teratogenic effects of maternal antiepileptic drugs (AEDs) on the development of the fetus are of major concern. The fetal risks imposed by these drugs must be weighed against the risks associated with untreated maternal epilepsy not being treated. Here, we describe an infant with a neural tube defect caused by AEDs prescribed to the mother during her pregnancy. A female infant was delivered by means of cesarean section after $37^{+6}$ weeks of gestation. Her 21-year-old mother had been diagnosed with epilepsy at 2 years of age, following brain surgery performed for a traffic accident injury. Since the age of 6 years, the mother had been medicated with lamotrigine $\left(\right.$ Lamictal $\left.^{\circledR}\right)$, levetiracetam $\left(\right.$ Keppra $^{\circledR}$ ), and valproate (Depakote ${ }^{\circledR}$ ). At birth, the baby exhibited pallor, severe macrocephaly, a large anterior fontanelle $(4 \mathrm{~cm} \times 4 \mathrm{~cm})$, and sutural widening. On her lower back, there was a $3 \mathrm{~cm}$ open spinal dysraphism exposing nervous tissue. On the $11^{\text {th }}$ postnatal day, a ventriculo-peritoneal shunt was placed and a myelomeningocele removal operation was performed. After this operation, the head circumference decreased from $44.0 \mathrm{~cm}$ to $35.8 \mathrm{~cm}$, and the post-operative period was uneventful. The patient was discharged on the $24^{\text {th }}$ day. Several case reports and studies have reported that valproate or multi-antiepileptic medication that contains valproate increased the risk of neural tube defects in the offspring. For women of childbearing age who use AEDs, clinicians should review pregnancy risk regularly and consider adjusting medication whenever possible. Additionally, while examing newborns with neural tube defects, clinicians should review prenatal maternal medication history thoroughly.
\end{abstract}

Keywords: Maternal-fetal relations; Hydrocephalus; Myelomeningocele; Neural tube defects; Drug prescriptions

\section{Introduction}

Most women with active epilepsy require treatment with antiepileptic drugs (AEDs) even during pregnancy. AEDs are also frequently used for other indications, such as migraine, pain syndromes, and psychiatric disorders, all of which are prevalent among women of childbearing age. The possible teratogenic effects of AEDs are therefore of major concern. The risks imposed by these drugs must be weighed against the risks associated untreated maternal epilepsy. Adverse drug effects on the fetus can include intrauterine growth retardation, congenital malformations, impaired postnatal development, behavioral problems, and fetal loss.

Here, we describe an infant with a neural tube defect (NTD) caused by AEDs prescribed to the mother during her pregnancy period. Medical records and data concerning this case were anonymized to protect the confidentiality of the patient.

\section{Case Report}

A female infant was delivered by means of a cesarean section after $37^{+6}$ weeks of gestation. Her 21-year-old mother had been diagnosed with epilepsy at 2 years of age, following brain surgery performed for a traffic accident injury. Since the age of 6 , the mother had been medicated with lamotrigine (Lamictal ${ }^{\circ}$ ), levetiracetam (Keppra ${ }^{\circ}$ ), and valproate (Depakote), and her medication was not changed during pregnancy period. She had not taken any type of folic acid. She experienced seizure attacks five times during this pregnancy, and the last episode occurred 5 weeks before delivery.

At birth, the baby weighed $2,850 \mathrm{~g}\left(36^{\text {th }}\right.$ percentile), was $51 \mathrm{~cm}$ long $\left(85^{\text {th }}\right.$ percentile) and had a head circumference of $44.0 \mathrm{~cm}$ (above $97^{\text {th }}$ percentile). The Apgar score was 3 and 5 at 1 minute and 5 minutes, respectively. Because of the infant's erratic respiratory drive, endotracheal intubation was performed at 3 minutes after birth.

On physical examination, she exhibited pallor, macrocephaly, a large anterior fontanelle $(4 \mathrm{~cm} \times 4 \mathrm{~cm})$, and sutural widening (Figure 1A). On her lower back, there was an open spinal dysraphism, exposing nervous tissue (Figure 1B).

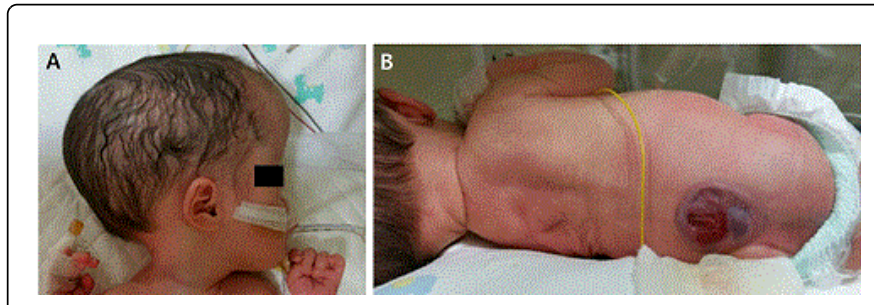

Figure 1: Clinical images of the newborn immediately after birth showing A: Macrocephaly with frontal bossing and B: Open myelomeningocele with exposed neural tissue. 
Citation: Lee J, Nam SK, Jun YH (2017) A New-born with Severe Hydrocephalus and Myelomeningocele Associated with Maternal Antiepileptic Medication: A Case Report. J Gen Pract (Los Angel) 5: 318. doi:10.4172/2329-9126.1000318

Page 2 of 3

No facial dysmorphism or deformities of the extremities were noted. Primitive reflexes, including suction and grasp reflexes, were intact. However, physical activity and muscle tone was diminished. She did not present any convulsion. Laboratory data were all within normal limits. A brain computed tomography scan performed on the $1^{\text {st }}$ day demonstrated massive dilation of both the lateral and $3^{\text {rd }}$ ventricles, consistent with a diagnosis of obstructive hydrocephalus. A brain MRI performed on the $2^{\text {nd }}$ day confirmed these dilations, predominantly at the posterior horn, but also revealed a normal-sized $4^{\text {th }}$ ventricle and bilateral cerebellar tonsilar herniation through the foramen magnum. Furthermore, there was agenesis of the septum pellucidum and the corpus callosum (Figure 2).
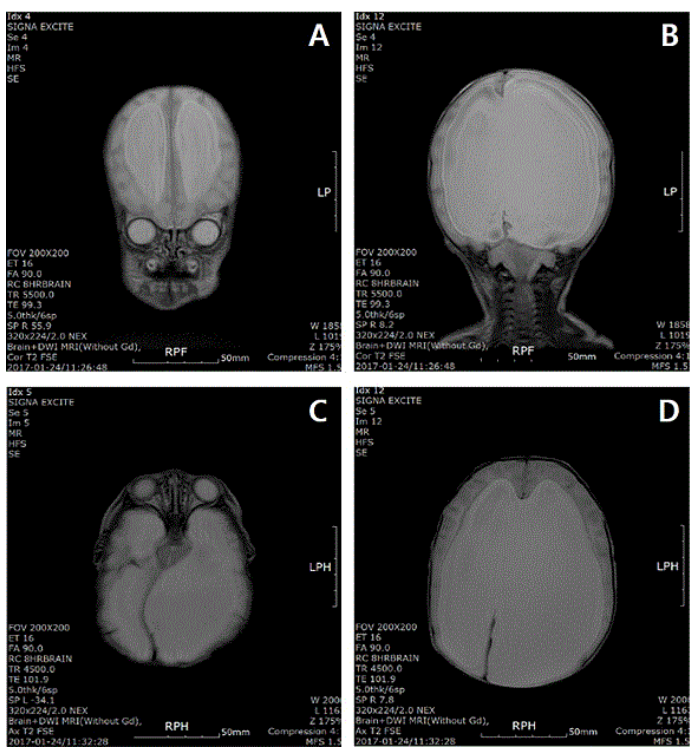

Figure 2: Brain MRI showing the dilation of both the lateral and 3rd ventricles and the agenesis of the septum pellucidum and the corpus callosum. A and B: Coronal view, C and D: Transverse view.

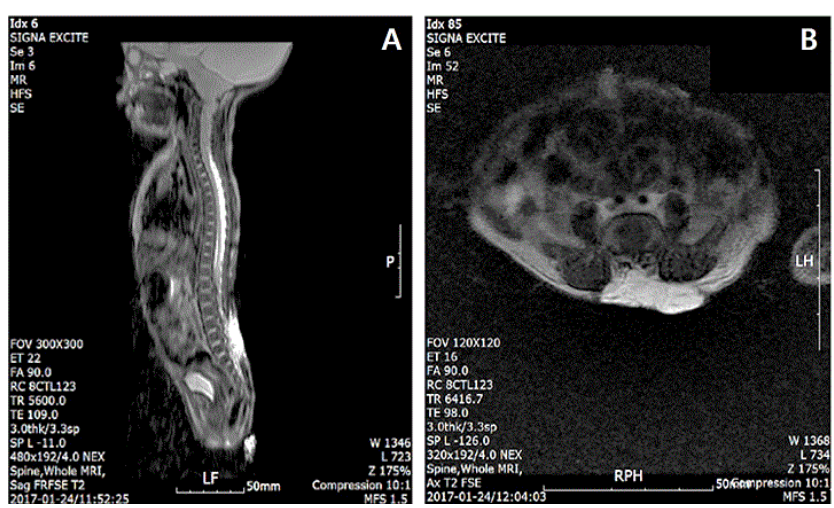

Figure 3: Spine MRI showing the lumbosacral myelomeningocele. A: Sagittal view, B: Transverse view.

From a spine MRI, lumbosacral myelomeningocele (open spinal dysraphism) was noted from L3 to S2. The size of the dysraphism was $3.0 \mathrm{~cm} \times 1.0 \mathrm{~cm} \times 3.1 \mathrm{~cm}$ (transverse $\times$ anterioposterior $\times$ craniocaudal dimensions), with a bony defect of the posterior element of the vertebrae from L3 to S1 (Figure 3).

The myelomeningocele contained the neural placode and nerve roots originating from the ventral placode surface stretched posteriorly.

The newborn's respiration was stabilized shortly, and she was extubated the day after birth. For the open spinal dysraphism, she was treated with piperacillin/sulbactam (Tabactam ${ }^{\circ}$ ) and povidone iodine wet dressing to prevent nerve tissue infection. On day 11 post-birth, a ventriculo-peritoneal shunt was placed and a myelomeningocele repair operation was performed. After this operation, the head circumference reduced from $44.0 \mathrm{~cm}$ to $35.8 \mathrm{~cm}$, and the post-operative period was uneventful. The patient was discharged on the $24^{\text {th }}$ day (Figure 4 ).

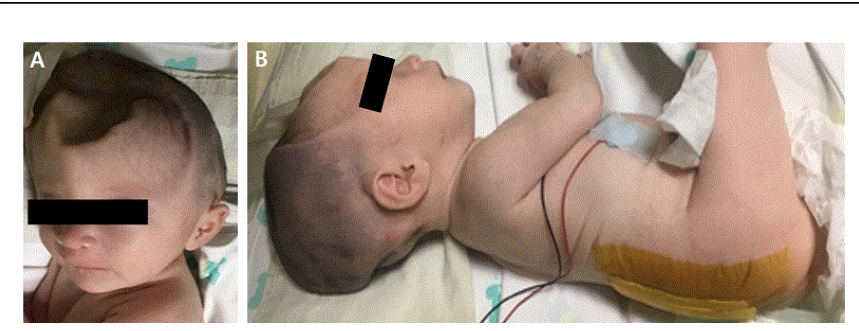

Figure 4: Clinical images of the newborn after a ventriculoperitoneal shunt was placed and the myelomeningocele repair operation was performed.

\section{Discussion}

The prevalence of congenital and infantile hydrocephalus is between 0.48 and 0.81 per 1000 births (live and still). Following successful treatment, a significant percentage of these patients are still left with persistent neurological deficits $[1,2]$. The causes of hydrocephalus vary, but the predominant causes are aqueductal stenosis and myelomeningocele. Poor cognitive function and visual loss are potential complications in infants with untreated hydrocephalus. Additionally, consequential impairments can also persist after treatment and interfere in the patient's development during a crucial time of growth [3-5]. Brain computed tomography and MRI are typically used to confirm the extent of the condition and its combined anomalies. While ultrasonography is also a sensitive imaging tool, it does not rule out structural anomalies of the brain. Treatment depends on the causes of the hydrocephalus, but a ventriculo-peritoneal shunt is the standard treatment despite the high risk of complications (approximately 50\%). The most common complications are shunt blockage and shunt infection. Other complications are also possible, namely, shunt migration, shunt malfunction, and pseudo cyst formation [5].

This case highlights the teratogenic effects of AEDs use in pregnant women. The risk of major fetal malformations in mothers with epilepsy using AEDs is approximately 6\%-8\%. This risk exceeds those found in women with untreated epilepsy $(2 \%-5 \%)$ and in the general population (2\%-4\%) [6]. The most common major congenital malformations associated with AEDs are NTDs, congenital heart disorders, urinary tract and skeletal abnormalities and cleft palate [7-9]. Congenital heart defects and, to a lesser extent, cleft palate have been observed in infants of patients treated with phenobarbital, phenytoin and primidone. NTDs and hypospadias have been mostly associated with valproate 
[10,11], and a facial cleft with lamotrigine [12]. Neurodevelopmental delay, behavioral disorders, or learning disabilities as an outcome of in utero exposure to valproate, have also been observed [13]. Lamotrigine or carbamazepine monotherapy at lower doses have been known to show the least risk of fetal major congenital malformation [9].

In women with epilepsy who are taking medications, the risk of major congenital malformation to the fetus is dependent on the type, number and dose of drugs [9]. Therefore, drug tailoring is necessary for these women during pregnancy. The dose of the chosen drug(s) should be minimized, as there is a clear relationship between the dose of these drugs (for example, valproate) and teratogenic effect. The total dose of valproate (and possibly other drugs) should be divided and prescribed three or four times a day to minimize high peak concentrations of the parent drug or its metabolites. Where possible, single drug therapy should be used, as the risks of teratogenicity are clearly shown to be greater in multi-drugs therapy (6\%-9\%) than in monotherapy (4\%-6\%) [14]. Women taking valproate with other drugs should have a detailed discussion with an epilepsy specialist on the risks and benefits of continuing or changing their AEDs prior to planning pregnancy. Where possible, valproate should be avoided. However, if the risk of maternal seizure deterioration from changing the medication is deemed to be high, women may need to be advised to continue valproate or multi-drug therapy [15].

In the present case, the mother was treated with multi-drugs therapy, so a clear correlation of the teratogenic effects of each drug was not possible. However, many other studies have consistently found malformation rates to be 2 to 3 times higher with valproate than with carbamazepine or lamotrigine. Various case reports and studies of valproate treatment during pregnancy have suggested that valproate increases the fetal risk of NTDs. Recently, a meta-analysis evaluated 13 controlled cohort studies on first-trimester exposure to valproate, comprising almost 1000 exposed babies. They reported that exposure to valproate was associated with a relative risk of 2 for major malformation (95\% CI: 1.33-2.99) when compared to all other antiepileptic drugs [16]. When compared to a healthy controls group representing the general populations, the relative risk was 4.37 (95\% CI: 2.84-6.71) [16].

In addition, the mother of this case had not been prescribed folate either prior to or during pregnancy. Given the potential benefit of folate on long-term cognitive outcomes and its known safety and effectiveness for preventing major congenital malformation, it is advised that women using antiepileptic medications should be prescribed high-dose folic acid (5 mg) daily from at least 3 months prior to conception to the end of the first trimester [15].

\section{Conclusion}

This case provides important insights into the linking infants with major congenital anomalies and prenatal exposures to maternal medications. Larger population-based studies on mothers and their babies are required to reveal these associations, including not yet identified. While, in the practice, for women of childbearing age who are already receiving antiepileptic treatment, clinicians should review the risk of teratogenic effects during pregnancy regularly and consider revising their prescription whenever possible. Ideally, treatment revisions should be made prior to conception. Furthermore, clinicians who observe a new-born baby with major congenital anomaly should review the mother's medication history for possible teratogenic AEDs.

\section{Acknowledgment}

This study was supported by an Inha University Hospital Research Grant.

\section{References}

1. Blackburn BL, Fineman RM (1994) Epidemiology of congenital hydrocephalus in Utah, 1940-1979: Report of an iatrogenically related “epidemic". Am J Med Genet 52: 123-129.

2. Fernell E, Hagberg G, Hagberg B (1994) Infantile hydrocephalus epidemiology: An indicator of enhanced survival. Arch Dis Child Fetal Neonatal Ed 70: F123-F128.

3. Feng H, Huang G, Liao X, Fu K, Tan H, et al. (2004) Endoscopic third ventriculostomy in the management of obstructive hydrocephalus: An outcome analysis. J Neurosurg 100: 626-633.

4. Aschoff A, Kremer P, Hashemi B, Kunze S (1999) The scientific history of hydrocephalus and its treatment. Neurosurg Rev 22: 67-93.

5. Sandberg DI (2008) Endoscopic management of hydrocephalus in pediatric patients: A review of indications, techniques, and outcomes. J Child Neurol 23: 550-560.

6. Beghi E, Annegers JF, Collaborative group for the pregnancy registries in epilepsy (2001) Pregnancy registries in epilepsy. Epilepsia 42: 1422-1425.

7. Hernández-Díaz S, Werler MM, Walker AM, Mitchell AA (2000) Folic acid antagonists during pregnancy and the risk of birth defects. $\mathrm{N}$ Engl J Med 343: 1608-1614.

8. Meador K, Reynolds MW, Crean S, Fahrbach K, Probst C (2008) Pregnancy outcomes in women with epilepsy: A systematic review and meta-analysis of published pregnancy registries and cohorts. Epilepsy Res 81: 1-13.

9. Tomson T, Battino D, Bonizzoni E, Craig J, Lindhout D, et al. (2011) Dose-dependent risk of malformations with antiepileptic drugs: An analysis of data from the EURAP epilepsy and pregnancy registry. Lancet Neurol 10: 609-617.

10. Lindhout D, Omtzigt JG (1992) Pregnancy and the risk of teratogenicity. Epilepsia 33: S41-S48.

11. Alsdorf R, Wyszynski DF (2005) Teratogenicity of sodium valproate. Expert Opin Drug Saf 4: 345-353.

12. Holmes LB, Baldwin EJ, Smith CR, Habecker E, Glassman L, et al. (2008) Increased frequency of isolated cleft palate in infants exposed to lamotrigine during pregnancy. Neurology 70: 2152-2158.

13. Nicolai J, Vles JS, Aldenkamp AP (2008) Neurodevelopmental delay in children exposed to antiepileptic drugs in utero: A critical review directed at structural study bias. J Neurol Sci 271: 1-14.

14. Morrow J, Russell A, Guthrie E, Parsons L, Robertson I, et al. (2006) Malformation risks of antiepileptic drugs in pregnancy: A prospective study from the UK Epilepsy and Pregnancy Register. J Neurol Neurosurg Psychiatry 77: 193-198.

15. https://www.rcog.org.uk/en/guidelines-research-services/guidelines/ gtg68/.

16. Campeanu S, Koren G, Nulman I (2005) Neural tube defect rates following in utero exposure to valproic acid. JFAS Int 3: e19. 